\title{
Editorial
}

\section{La reforma tributaria: alcances y limitaciones}

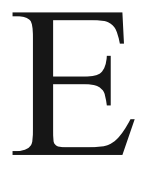

n los últimos días de 2014, el presidente de la República sancionó la nueva reforma tributaria (Ley 1739 de 2014) que rige a partir de enero de 2015, la cual, según Santos, "no afecta a la clase media del país ni a las pequeñas ni medianas empresas". El presidente insistió, además, en que los nuevos ingresos tributarios "se destinan a inversiones sociales y productivas".

En principio se dijo que era un proyecto de ley de financiamiento para el presupuesto de 2015, que estaba desfinanciado en $\$ 12.5$ billones, pero, al final, se transformó en una importante reforma tributaria para el próximo cuatrienio.

En la discusión en el Congreso de la República, el proyecto fue muy criticado tanto por analistas como por empresarios, y llevó a enfrentamientos del Gobierno con los gremios económicos, incluso con aquellos que se habían caracterizado por apoyar las iniciativas gubernamentales. Con la nueva ley, el impuesto al patrimonio que terminó su vigencia en 2014, se transformó en impuesto a la riqueza que pagarán 32.000 sociedades y 52.000 personas naturales ${ }^{1}$.

Es importante anotar que las tarifas son marginales y progresivas. Veamos para el año 2015, si tomamos el caso de las empresas, los primeros $\$ 2.000$ millones (una tasa de $0,20 \%$ ), de $\$ 2.000$ a $\$ 3.000$ millones (de $0,35 \%$ ), de $\$ 3.000$ a $\$ 5.000$ millones (de 0,75\%), de $\$ 5.000$ millones en adelante (de 1,15\%). Para las personas naturales, también en el año 2015, las tarifas para los primeros $\$ 2.000$ millones (una tasa de $0,125 \%$ ), de 2.000 a 3.000 millones (de $0,35 \%$ ), de $\$ 3.000$ a $\$ 5.000$ millones (de $0,75 \%$ ) y de $\$ 5.000$ millones en adelante (de $1,50 \%$ ).

Para el periodo en que estará vigente el impuesto a la renta, las empresas pagarán un máximo de $1,15 \%$ en 2015, de $1 \%$ en 2016, de $0.4 \%$ en 2017 y en 2018 se eliminará dicho impuesto. En cambio, las personas naturales en el periodo comprendido entre 2015-2018, pagarán un máximo anual de $1.5 \%$.

Por otra parte, se mantiene el impuesto del 4 por mil, que al igual que el del patrimonio, expiraba en 2014; en la Ley 1739 quedó estipulado su desmonte a partir del 2019. Para ese año bajaría a tres por mil, descendería al 2 por mil en 2020 y en 2021 sería de 1 por mil, a partir del 2022 desaparecería.

\footnotetext{
Debe precisarse que por riqueza se entiende el total de patrimonio bruto menos las deudas a cargo del contribuyente, y además, el monto cancelado por este impuesto no será descontado del de renta, ni del de CREE (impuestos sobre la renta para la equidad). Tanto para las sociedades como para las empresas, la base gravable se aplicará a aquellos sujetos tributarios que el primero de enero de 2015 tengan un patrimonio líquido igual o superior a \$1.000 millones. En el caso de las personas jurídicas, el mencionado impuesto se pagará hasta 2017 y las naturales lo harán hasta 2018.
} 
Es de anotar que la reforma modificó el IMAS (impuesto mínimo alternativo simple), creado por la Ley 1607 de 2012. Esta alteración consistió en reducir el umbral del IMAS. La decisión afectará a los asalariados, ya que con la reforma tributaria anterior los trabajadores podían optar por el IMAS, siempre y cuando tuvieran una renta gravable inferior a 4.700 unidades de valor tributario -UVT- (aproximadamente 126 millones de pesos). En la actual reforma, el límite se bajó a 2800 UVT (aproximadamente 79 millones de pesos). Esta decisión se tomó debido a que la DIAN detectó en las declaraciones de renta de 2013, un número considerable de contribuyentes que aplicaron el IMAS y tuvieron saldos a favor, en especial aquellos que devengaban un salario mensual entre \$5.9 y \$12.9 millones. De hecho, si se reduce el límite del IMAS, muchos contribuyentes se inclinarán por el IMAN (impuesto mínimo alternativo nacional), siendo muy probable que en vez de tener saldos a favor, después de la liquidación, obtengan saldos a pagar.

También se creó un impuesto de normalización tributaria, el cual tendrá vigencia para los años 2015-2017, para que aquellos contribuyentes que en las declaraciones de renta pasadas no hayan incluido todo sus activos, lo hagan y normalicen su situación con el fisco. Esta alternativa es muy importante, ya que la evasión y la elusión tributaria en Colombia son muy altas. Según la DIAN, la evasión del IVA es del $40 \%$ y del impuesto de renta del $50 \%$, lo que representa, aproximadamente, $\$ 50$ billones. Si redujéramos sustancialmente dicha práctica, tendríamos los recursos suficientes y no nos veríamos en la necesidad de hacer una reforma tributaria cada dos años.

Para algunos analistas y empresarios, el hecho de cambiar el impuesto al patrimonio por el impuesto a la riqueza se hizo para tener en cuenta los planteamientos de Thomas Piketty en su libro $\mathrm{El}$ capital en el siglo XXI. Este autor afirma que la tasa de crecimiento de la economía es menor que la tasa de rendimiento del capital, por ello, la concentración de la riqueza es cada vez mayor y la única forma de combatirla es gravando directamente el capital. Sin embargo, es bueno aclarar que el impuesto al patrimonio existe desde el 2002 -creándose para financiar la guerra-; ahora lo ideal es que si se consolida el proceso de paz, con los recursos que genere el mencionado impuesto, se sufragarán los gastos del posconflicto. A pesar de ello, la desigualdad económica en Colombia es considerable, pues tenemos un coeficiente de Gini de 0.54 (uno de los países más inequitativos del mundo), es decir, el ingreso y la riqueza se concentran en unos pocos.

La actual reforma tributaria no gravó los dividendos de los propietarios de empresas, porque en el Congreso se argumentó que al hacerlo se incurría en la doble tributación, mientras que los ingresos laborales al bajar el tope del IMAS, van a tener un gravamen fuerte y, por tanto, la reforma no contribuirá a la equidad distributiva, ya que la estructura tributaria vigente favorece las rentas de capital y afecta negativamente las rentas de trabajo.

Tal vez, lo más importante de la última reforma es la recomendación de conformar una comisión que le proponga al país una reforma tributaria integral, entendida esta, como aquella que cubra en su totalidad la tributación que hacen las personas y las empresas, y además garantice criterios de equidad y progresividad. Empero, hasta qué punto en dicha comisión imperarán los intereses creados. Todo dependerá de quiénes la integren y cuáles sean sus orientaciones ideológicas, así como hasta qué punto sus apreciaciones sean técnicas y objetivas o respondan a intereses particulares. 